\title{
False recognition across meaning, language, and stimulus format: Conceptual relatedness and the feeling of familiarity
}

\author{
TEDRA FAZENDEIRO \\ University of Denver, Denver, Colorado \\ PIOTR WINKIELMAN \\ University of California, San Diego, La Jolla, California \\ and \\ CHUN LUO and CHRISTOPHER LORAH \\ Wesleyan University, Middletown, Connecticut
}

\begin{abstract}
Four experiments examined contributions of conceptual relatedness and feelings of familiarity to false recognition. Participants first studied lists of unrelated items (e.g., table, lock) followed by a recognition test with three types of items: (1) studied items (e.g., table), (2) semantically related lures (e.g., key), and (3) unrelated lures (e.g., cup). Participants falsely recognized more related than unrelated lures when the stimuli were words (Experiment 1A) and pictures (Experiment 1B), when the studied items and related lures differed in language (Experiment 2), and when they differed in perceptual format (Experiment 3). In Experiment 4, an attribution manipulation, designed to make feelings of familiarity nondiagnostic for memory judgments, eliminated the false-recognition effect obtained in Experiment 3. Overall, the study suggests that conceptual relatedness produces false recognition even in the absence of shared perceptual surface features between study and test items, and it does so by generating feelings of familiarity.
\end{abstract}

Memory illusions capture the attention of psychologists and the general public. A frequently studied type of memory illusion occurs when a person "recognizes" a test item that was never presented at study. The present research explores three questions about false recognition: First, does false recognition occur when a critical test item is only conceptually related to the study item, even if the test item is presented in a different physical format or in a different language than the study item? Second, does false recognition occur even when a critical item is only weakly prepared by a single conceptually related study item? Third, is false recognition of conceptually related items supported by a distinct feeling of familiarity, and can it be eliminated by making that feeling nondiagnostic for recognition judgment? Answers to these questions will help us better to understand the scope and mechanisms of memory illusions.

This research was supported by National Science Foundation Grant BCS-0217294 to P.W. We thank Charles Brainerd, Tim Curran, David E. Huber, John G. Seamon, Bruce Whittlesea, John Wixted, and the Cognitive Research Group at the University of Denver for helpful discussions about this research and comments on previous versions of the article. Correspondence concerning this article should be addressed to T. Fazendeiro, Department of Psychology, 2155 S. Race St., University of Denver, Denver, CO 80210 (e-mail: tfazendeiro@nova.psy.du.edu).

\section{Perceptual and Conceptual Contributions to False Recognition}

To explain false recognition, previous research often focused on perceptual fluency, or the ease of processing a stimulus's physical identity (e.g., Jacoby \& Dallas, 1981; Johnston, Hawley, \& Elliot, 1991; Lindsay \& Kelley, 1996; Rajaram, 1993; Verfaellie \& Treadwell, 1993). Several studies have found that false recognition can be enhanced with simple perceptual manipulations, such as subliminally priming the test word with an identical word (e.g., Jacoby \& Whitehouse, 1989); increasing clarity of the test word (e.g., Whittlesea, Jacoby, \& Girard, 1990); or having participants perform a perceptual task, such as fragment completion, on the test item (e.g., Luo, 1993). Presumably, these manipulations enhance false recognition because greater perceptual fluency of the nonstudied test item is misattributed to its presentation during study (Jacoby, Kelley, \& Dywan, 1989). Accordingly, falserecognition rates are reduced when participants have an alternative explanation for the enhanced fluency, as when, for example, the test word is preceded by an easily visible prime (Jacoby \& Whitehouse, 1989).

False recognition is also susceptible to conceptual influences. Whittlesea (1993) found that test words (e.g., boat) were falsely recognized at a higher rate when preceded by semantically predictive sentence stems (e.g., The stormy seas tossed the ...) than when preceded by 
nonpredictive stems (e.g., She saved her money and bought $a$...). Presumably, the predictive stem unobtrusively enhances conceptual fluency of the test word, which is then misattributed to the study episode (Whittlesea, 1993). Conceptual influences on false recognition have also been explored using a converging associates paradigm, also known as the Deese, Roediger, and McDermott (DRM) paradigm. In this paradigm, participants study a list of semantic associates (e.g., table, sit, legs, seats, etc.) that converge on one nonstudied lure (e.g., chair). In a memory test, the related lure is both falsely recalled (Deese, 1959) and falsely recognized at a rate comparable to words actually presented at study (Roediger \& McDermott, 1995; Seamon, Luo, \& Gallo, 1998). The conceptual nature of the DRM phenomenon is suggested by several findings. Large false-recognition effects (60\%-70\% false alarms) can be obtained even when the perceptual modality of the words differs between study and test episodes, as when auditory presentation at study is changed to visual presentation at test (Gallo, McDermott, Percer, \& Roediger, 2001). Recently, Whittlesea (2002) reported that the presentation of a list of converging associates enhances conceptual processing of a related lure, as reflected in faster lexical decisions, but does not enhance perceptual processing of that lure, as reflected in unchanged naming latencies (Chumbley \& Balota, 1984).

\section{The Present Research}

The research just reviewed suggests that false recognition can be enhanced by immediately preceding the target item with a semantically predictive context or by presenting the multiple semantic associates earlier. The present research builds upon these findings in several ways.

Conceptual relatedness. There are several theoretical accounts of false-recognition effects. These include implicit activation of related lures (e.g., Roediger, Balota, \& Robinson, 2002; Seamon et al., 2002), generation of a gist trace (Brainerd, Reyna, Wright, \& Mojardin, 2003), the global matching hypothesis (Hintzman, 1988), and misattribution of processing fluency to the study episode (Jacoby \& Dallas, 1981; Whittlesea, 2002). All of these accounts agree that false recognition should require only a conceptual relation between study and test items. Interestingly, however, most previous work manipulated relatedness of study and test items within the same physical modality (e.g., visual presentation of related words) or within the same stimulus format (e.g., visual and auditory presentation of the same words). There are several reasons to investigate the false-recognition effects across more purely conceptual relations.

First, selective facilitation of conceptual, but not perceptual, stages of stimulus processing may produce robust false-recognition effects. This prediction is somewhat paradoxical. After all, a change in surface-level features weakens perceptual activation of the target item and should thus reduce false recognition. However, according to the discrepancy attribution theory, nonfluent perceptual processing can actually make fluent concep- tual processing particularly surprising and, as a result, elicit strong feelings of familiarity (Whittlesea, 2002). Robust false-recognition effects are also predicted by the fuzzy trace theory (Brainerd et al., 2003). For this theory, changes in surface-level features make it difficult to recall verbatim traces from the study list that could be used to reject related lures correctly (a process called "recollection to reject"). As a result, even weak activation of related lures can lead to robust semantic false recognition.

The second reason to investigate false recognition across more purely conceptual relations is that in previous studies, prime words (whether in study lists or predictive sentences) could activate related test words via lexical but not semantic representations (Weldon, Roediger, Beitel, \& Johnson, 1995). Stronger evidence for the role of conceptual relatedness would be obtained with more dramatic changes in stimulus format and language, as discussed shortly.

Finally, investigating false recognition across conceptually related stimuli has a potential applied importance. For example, in many real-world situations, a person may experience the material visually and then be queried about it verbally. Understanding whether false recognition occurs despite such a transfer in stimulus format may shed light on the power of memory illusions.

Present manipulations. The four experiments of the present article examined false recognition with manipulations that increasingly detached the related study and test items in terms of their surface features. In Experiments $1 \mathrm{~A}$ and $1 \mathrm{~B}$, we established basic parameters of the phenomenon by exploring enhanced false recognition for words that are semantically related to words from the study list (Experiment 1A) and false recognition for pictures that are semantically related to pictures from the study list (Experiment 1B). In Experiment 2, we relied on bilingual individuals and presented study words and their semantic associates at test in different languages. Past research on adult bilinguals suggests that there are separate lexical representations for each of the two languages, whereas the semantic representation is shared (see Smith, 1991, for a review). For example, semantic priming occurs across languages, but lexical priming occurs only within languages (Caramazza \& Brones, 1980; Smith, 1991; Watkins \& Peynircioğlu, 1983). Thus, if participants falsely recognize related lures presented in a different language than their studied associates, this result is likely due to processes at the conceptual rather than the lexical level. Finally, in Experiments 3 and 4, we presented semantically related study and test items in two different perceptual modalities (words vs. pictures). Such presentation ensured that the conceptual links remained but that the contributions of both perceptual and lexical processes were minimized. In sum, demonstrating false recognition across these varying manipulations would strongly argue for the independent influence of conceptual processes on memory illusions.

Single-pair paradigm. How much conceptual preparedness is required to elicit false recognition? Many 
studies use the DRM paradigm, in which several (e.g., 18) converging associates are presented at study (Roediger \& McDermott, 1995). Other studies use only a single related item but present the item immediately before the target (Whittlesea, 1993). However, according to the fuzzy trace, implicit activation, and conceptual fluency accounts, even a single study word should influence subsequent processing of related test items, even if those items are presented after a delay. Obviously, under comparable conditions, lure processing is facilitated less by a single related item than by 18 related items. Nonetheless, note that according to the discrepancy attribution theory, it is not the absolute level of processing facilitation that matters, but the relation of the facilitation to the processing expectation for that item (Whittlesea \& Williams, 1998). Thus, a relatively weak facilitation of conceptual processing, even with one item, should lead to false recognition in paradigms that ensure relatively nonfluent perceptual processing. Furthermore, presentation of single, unrelated items in a list without any theme should prevent participants from forming any expectation about the lures, thus making their facilitated processing particularly surprising (Whittlesea, 2002). Finally, the likelihood that studying a single associate will induce false recognition of lures at test should be promoted by conditions that minimize surface processing at study. This is because meaning information is likely to be processed in the absence of full surface-level processing. Accordingly, to enhance semantic false recognition, the present experiments used relatively short stimulus durations at study (e.g., $250 \mathrm{msec}$ ) as opposed to the longer (e.g., $1 \mathrm{sec})$ durations used in much of the previous research (Seamon et al., 2002). In sum, we predict that reliable false recognition will occur when each lure in the test is semantically related to only a single study item.

The paradigm used in the present study will hereafter be called the single-pair paradigm. Grossman and Eagle (1970) demonstrated false recognition using a similar but not identical paradigm. First, we use a more stringent test of false recognition than they did, by presenting each study list item only once, in contrast to Grossman and Eagle's repetition of each study word. Second, for reasons already discussed, we take the paradigm beyond a single modality or stimulus format; Grossman and Eagle presented all word stimuli in the auditory modality. In contrast, we first replicate their results with visual presentation of words in Experiment $1 \mathrm{~A}$ and then extend this false-recognition effect to pictorial stimuli in Experiment 1B. In Experiment 2, we use cross-language visual presentation of words, and in Experiments 3 and 4, we present test pictures and words in a different stimulus format than the conceptually related study items.

A demonstration of false-recognition effects using the single-pair paradigm is important in several ways. If single-word priming enhances false recognition not only across semantic associates, but also across language and perceptual format, this result would suggest that memory illusions require only a minimal encounter with the study item and can survive drastic changes in item appearance. Furthermore, demonstrating false recognition with the single-pair paradigm adds to the converging evidence of the implicit nature of false recognition. If participants "recognize" weakly prepared items and do so despite dramatic changes in the items' appearances, it is unlikely that the participants are relying on strategic processes, at least in the sense of strategically generating a semantically related item in a different perceptual modality or a different language.

Subjective experience. Finally, we investigated the role of subjective experiences underlying false recognition. Specifically, what kind of "experience," if any, leads participants to judge a related lure as "old"? According to one view, in the context of a memory task, fluent processing of lures is unconsciously attributed to the past encounter and elicits a conscious experience of familiarity (Jacoby et al., 1989; Whittlesea \& Williams, 1998). In other contexts, the same fluent processing may be unconsciously attributed to other properties, resulting in a different conscious experience, such as liking (Reber, Winkielman, \& Schwarz, 1998), loudness (Jacoby, Allan, Collins, \& Larwill, 1988), or stimulus duration (Masson $\&$ Caldwell, 1998). This process is analogous to the twofactor theory of emotion, which proposes that heightened arousal leads to qualitatively different conscious feelings depending on contextual cues (Schachter \& Singer, 1962). However, there are several alternatives to the idea that conceptually fluent items generate a feeling of familiarity. One possibility is that participants have a nonspecific feeling of processing ease-an experience we hence refer to as subjective fluency. That is, participants might feel that some test items come to mind more easily and judge those items as "old" on the basis of that feeling. This possibility is analogous to proposals in the emotion literature that participants use their undifferentiated arousal to judge stimuli, without the arousal necessarily resulting in qualitatively different experiences depending on contextual cues (Reisenzein, 1983). This possibility is related to proposals that a general "nonspecific activation" underlies a variety of stimulus judgments (Mandler, Nakamura, \& Van Zandt, 1987). Finally, it is possible that participants do not have any feelings when encountering conceptually related items and simply base their memory judgments on nonexperiential criteria. This possibility predicts that manipulations targeting the validity of experiences should not influence rates of false recognition. These questions were investigated in Experiment 4 with a misattribution manipulation adapted from the emotion literature (Schachter \& Singer, 1962; Schwarz \& Clore, 1996). On the basis of the logic of the two-factor model, we predict that an attribution manipulation implying that a familiarity experience is nondiagnostic for memory judgments will selectively lower the rate of semantic false recognition. Conversely, we predict that manipulations targeting an experience of subjective fluency or nonspecific feelings will not influence rates of false recognition. 
To summarize, the goals of the present research were as follows: We examined the role of conceptual relatedness in false recognition using increasing levels of perceptual detachment between semantically related study and test items (i.e., across word and picture formats and across languages). Furthermore, we examined the strength of conceptual influence on false recognition using a single-pair recognition paradigm (as opposed to either a converging associates or an immediate priming paradigm). Finally, we examined the nature of subjective experience generated by conceptually related items using attribution manipulations.

\section{EXPERIMENTS 1A AND 1B}

Experiments 1A and 1B served to establish the basic parameters of false recognition effects using a singlepair paradigm in which each lure was semantically related to a single item from the study list. Specifically, Experiment $1 \mathrm{~A}$ used this paradigm to explore false recognition for words, whereas Experiment 1B examined false recognition with pictures. Both experiments also served as pretests for Experiment 3, which investigated false recognition of semantic associates presented across changes in perceptual format (words to pictures and pictures to words). The basic paradigm in all experiments was as follows: Participants were presented with lists of unrelated study items. Each study list was followed by a recognition test consisting of three types of test items: (1) studied items, which actually appeared in the study list; (2) related lures, which were not presented at study, but were semantically related to one of the studied items (i.e., they were paired associates of studied items); and (3) unrelated lures, which were unrelated to any of the studied items. False recognition was signaled by a higher rate of false alarms to related lures than to unrelated lures.

\section{Method}

Participants and Materials. Twenty Wesleyan University undergraduates participated in Experiment $1 \mathrm{~A}$ and 20 in Experiment $1 \mathrm{~B}$, for course credit. To construct the study and test lists, the names and line drawings of 192 common objects and animals were taken from Snodgrass and Vanderwart's (1980) standardized set of 260 pictures. Experiment $1 \mathrm{~A}$ used only words, and Experiment 1B used only pictures. In both experiments, materials were constructed using the following method: First, 64 items were selected to form 32 pairs of associates. A complete list of these paired associates is shown in Appendix A. One of the items in each pair of associates was a study item, the other was a test item. The 32 items chosen for presentation at study were randomly distributed among four separate study lists, so that each study list contained 8 associates. An additional 96 items were randomly selected and distributed evenly among the four study lists. Therefore, each of the four study lists contained 32 items, for a total of 128 items shown at study. To eliminate the possibility of semantic association among study items, special care was taken to adjust the lists to ensure that none of the study items in the same list were semantically related to each other.

The four test lists each consisted of 32 items, 16 of which had been presented in the study list (studied) and 16 of which had not been presented (nonstudied). Of the 16 nonstudied items, 8 were related lures, which were semantically related to one item in the study list (e.g., study table, test chair). The 8 additional nonstudied items in each of the four test lists were unrelated lures, which were not semantically related to any of the study list words. Studied, related, and unrelated test categories consisted of distinct items. For example, the test item chair was always a related lure and never a studied item or an unrelated lure. Furthermore, test lists never included the studied associates of related lures (e.g., table for the related lure chair).

Procedure. The participants were tested individually, with all materials presented on a computer. Beginning instructions asked the participants to remember as many study items as possible for a later recognition test. The participants were informed that some of the test items would be "old," meaning that they were presented in the previous study list, and some of the test items would be "new," meaning that they were not presented in the study list. The participants were not informed about the semantic relatedness of some test items to some study items. After the beginning instructions, the participants were presented with the first list of 32 items to study. The study items were presented one at a time in the center of the computer screen at a rate of $250 \mathrm{msec}$ per item. The word stimuli (Experiment 1A) were printed in black, uppercase, 24-point, bold, Helvetica font on a white background. The pictorial stimuli (Experiment 1B) consisted of line drawings presented within a $3 \times$ 2 -in. white space in the center of the computer screen. The 32-item recognition test list followed immediately. The test items were presented one at a time, and each item remained on the screen until the participant made a recognition judgment on the keyboard. The participants were told to press the key labeled OLD for any item that they recognized as having appeared in the previous study list or the key labeled NEW for any item they did not recognize. After this "old" or "new" judgment, a screen prompt asked the participants to make a "remember," "know," or "not applicable" judgment by pressing the keys labeled $\mathrm{R}, \mathrm{K}$, or N/A, respectively. The participants were told that if they had indicated that an item was "old," they should press either R or K. More specifically, they were told to press R if they had conscious recollection of the item's occurrence in the previous study list or of what they were thinking about at the time the item was presented. They were told to press $\mathrm{K}$ if they were sure that the item was presented in the study list but could not consciously recollect its actual appearance or any other details regarding its occurrence in the list. On the other hand, the participants were told that if they had responded that an item was "new," they should press the key labeled N/A, because the remember-know question would not be applicable for the items that they did not recognize. The rememberknow instructions were similar to those used by other researchers (e.g., Gallo, Roberts, \& Seamon, 1997; Roediger \& McDermott, 1995; Seamon et al., 1998; see Tulving, 1985, for more on the remember-know distinction). Participants proceeded through all four of the study lists and the subsequent recognition tests until they were finished with the experiment. Each new study list was preceded by a 2-sec NEXT LIST prompt to ensure that the participants did not miss any study items. The procedures for Experiments 1A and $1 \mathrm{~B}$ were identical.

\section{Results and Discussion}

Experiment 1A: True and false recognition of word stimuli. The left columns of Table 1 show the mean proportions of recognized words and the corresponding remember-know judgments in Experiment 1A. An analysis of variance (ANOVA) revealed a significant main effect of item type (studied items, related lures, or unrelated lures) on recognition responses $\left[F(2,38)=153.76, M S_{\mathrm{e}}=\right.$ $0.008, p<.001]$. A further $t$ test revealed that the participants falsely recognized related lures at a significantly higher rate than unrelated lures $[t(19)=3.59, p<.01]$. 
Table 1

Experiments 1A and 1B: Mean Proportions of Test Items Judged "Old" (P) and Remember (R)-Know (K) Responses as a Function of Item Type and Perceptual Format (Words vs. Pictures)

\begin{tabular}{llllllll}
\hline & \multicolumn{3}{c}{ Words } & & \multicolumn{3}{c}{ Pictures } \\
\cline { 2 - 4 } \cline { 6 - 8 } Item Type & $\mathrm{P}$ & $\mathrm{R}$ & $\mathrm{K}$ & & $\mathrm{P}$ & $\mathrm{R}$ & $\mathrm{K}$ \\
\hline Studied & .63 & .34 & .29 & & .77 & .43 & .34 \\
Related & .26 & .08 & .18 & & .21 & .05 & .16 \\
Unrelated & .18 & .06 & .12 & & .13 & .04 & .09
\end{tabular}

Note-Words were presented in Experiment 1A. Pictures were presented in Experiment 1B.

Experiment 1B: True and false recognition of pictorial stimuli. The right columns of Table 1 show the mean proportions of recognized pictures and the corresponding remember-know judgments. An ANOVA revealed a significant main effect of item type on recognition $\left[F(2,38)=504.03, M S_{\mathrm{e}}=0.005, p<.001\right]$. A further $t$ test showed that participants falsely recognized related lures more often than unrelated lures $[t(19)=3.23, p<.01]$.

Comparison of recognition in Experiments 1A and 1B. As shown in Table 1, the hit rate was significantly greater for studied pictures than words $[t(38)=4.18$, $p<.001]$. Thus, data for true recognition reveals a picture superiority effect (e.g., Paivio, Rogers, \& Smythe, 1968). In contrast, the rate of false recognition for pictures did not significantly differ from that for words $(t<$ 1). In fact, the increase from unrelated to related lures in Experiments $1 \mathrm{~A}$ and $1 \mathrm{~B}$ was exactly the same (about .08). Still, we hasten to acknowledge that the present experiments had a relatively low power, and we cannot draw strong conclusions from the lack of difference between levels of semantic false recognition for pictures and words. Furthermore, in many cases, participants can avoid false recognition of pictures by relying on a distinctiveness heuristic and demanding a match in perceptual features between study and test (Israel \& Schacter, 1997). One reason such reliance could have been more difficult in the present research was the fast presentation rate $(250 \mathrm{msec})$, which may not have been sufficient to establish strong perceptual traces for pictures and which allowed greater use of semantic gist traces.

Remember/know judgments for Experiments 1A and 1B. The participants made more "remember" than "know" judgments for studied items. However, this difference failed to reach significance for words $(t<1)$ and was only marginal for pictures $[t(19)=1.63, p=.12]$. In contrast, participants made more "know" than "remember" judgments for both related words $[t(19)=$ 4.33, $p<.001]$ and unrelated words $[t(19)=2.73, p=$ $.01]$, as well as for related pictures $[t(19)=5.1, p<$ $.001]$ and unrelated pictures $[t(19)=2.72, p=.01]$. These results indicate that although participants falsely recognized related lures at a higher rate than unrelated lures, they were not more likely to indicate that they consciously remembered the occurrence of the related lures in the study list. Furthermore, this pattern held true re- gardless of whether stimuli were pictures or words. The participants did, however, make more "remember" judgments for studied pictures than for studied words $[t(19)=$ $2.4, p<.05]$, indicating that they were more likely to consciously remember pictures than words that appeared in the study list. This result is not surprising, given the picture superiority effect. Because remember-know results did not provide additional information beyond hits and false alarms that could help explain false-recognition effects in Experiments 1A and 1B, remember-know results will not be discussed for the remaining experiments.

To summarize, Experiments 1A and 1B demonstrated false-recognition effects for both words and pictures. These experiments showed that a minimal amount of conceptual preparedness, instantiated by the single-pair paradigm, is sufficient to induce significant false recognition of related lures. In Experiments 2 and 3, we investigated the power of this effect by further detaching the perceptual and lexical relationships of semantically related study and test items.

\section{EXPERIMENT 2}

Experiment 2 examined whether cross-language semantic priming leads to false recognition. For example, would bilingual participants falsely recognize silla (the Spanish word for chair) if they first studied the English word table? As discussed earlier, previous research on bilinguals suggests that different languages have separate lexical representations but a shared semantic representation (Smith, 1991). Thus, if false recognition is observed when related study and test items are presented in different languages, it would suggest that the underlying process involves a semantic, not a lexical, connection between related study and test items.

\section{Method}

Participants. The participants were 24 Wesleyan University undergraduates who responded to campus advertisements for bilingual Spanish and English speakers and were either paid $\$ 5$ or received course credit in return for their participation. All participants completed a short questionnaire to determine their level of bilingual proficiency. On a seven-point scale, the participants' selfreported level of bilingual proficiency was high $(M=5.3)$. Additional questions included which language the participants heard most often when growing up (English $n=12$, Spanish $n=12$ ) and in which language they do most of their cognitive operations (verbal and nonverbal; English $n=21$, Spanish $n=3$ ).

Materials. The study and test lists were the same as in Experiment 1, except that half of the words in each list were presented in English and half in Spanish, randomly intermixed. Likewise, studied, related, and unrelated test words consisted half of English and half of Spanish words. Studied test words were always presented in the same language as in the study list, but related lures were always presented in a different language than their studied associates (e.g., lock at study but llave, Spanish for key, at test). As in Experiment 1, the studied, related, and unrelated categories consisted of distinct items, so that llave, for example, was a related lure and never a studied item or unrelated lure.

Procedure. The procedure was identical to that in Experiment 1, except for a slight variation in the instructions. The participants 
were told that half of the words would be in Spanish and half would be in English, and that they should focus their attention equally on the words in both languages. In addition, the participants were told that for a test word to be judged "old," it should match in both meaning and the language in which it was presented at study.

\section{Results and Discussion}

Table 2 shows the mean proportions of test items judged "old" as a function of item type (studied items, related lures, and unrelated lures) and language of presentation at test. Note that the language indicated in the table is that in which the words were shown at test, and for all related lures in one language, their associates were presented in a different language at study. An ANOVA revealed a significant main effect of language at test $[F(1,46)=13.45$, $\left.M S_{\mathrm{e}}=0.237, p<.001\right]$ and of item type $[F(2,23)=4.70$, $\left.M S_{\mathrm{e}}=2.35, p<.001\right]$. The interaction of the two variables was not significant $(p<1)$. More importantly, further $t$ tests showed that participants falsely recognized related Spanish lures more than unrelated Spanish lures $[t(23)=$ $3.73, p<001]$. They also falsely recognized related English lures more than unrelated English lures $[t(23)=2.41$, $p<.03]$. These results indicate that the presentation of a single word at study caused participants to falsely recognize a semantically related lure in a different language at test. The fact that false recognition occurred even though associated study and test items were presented in different languages suggests that conceptual relatedness can elicit false recognition with minimal perceptual similarity or lexical activation of the nonpresented related lures.

\section{EXPERIMENT 3}

Experiment 3 further explored the power of conceptual influences on false recognition by presenting related lures in a different perceptual format from their associated study items. For example, would participants falsely recognize a picture of a chair if they first studied the word table? This issue is important to examine because, as discussed earlier, priming among semantic associates may involve perceptual and lexical representations (Weldon et al., 1995). If so, we should not expect false recognition of test items prepared by study items in a different format. More specifically, if perceptual similarity and lexical relatedness are required for false recognition, conceptually related test items in different perceptual formats should be rejected based on their lack of these relationships with associated study items. On the other hand, if conceptual

Table 2

Experiment 2: Mean Proportions of Test Items Judged "Old" as a Function of Item Type and Language at Test (English vs. Spanish)

\begin{tabular}{lcc}
\hline Item Type & English & Spanish \\
\hline Studied & .62 & .67 \\
Related & .26 & .37 \\
Unrelated & .19 & .26 \\
\hline
\end{tabular}

Note-For related lures, associates were presented in a different language at study. relatedness is sufficient for false recognition, participants should falsely recognize related lures even when they have no perceptual or lexical relationship with associated study items. In short, Experiment 3 provided a strong test of conceptual contributions to false recognition.

\section{Method}

Participants and Materials. Forty Wesleyan University undergraduates participated for course credit. The study and test lists were the same as in Experiment 1, except that half of the items in each list were presented as words and half as pictures, randomly intermixed. Likewise, the studied, related, and unrelated test items consisted half of words and half of pictures. Studied test words were always presented in the same format as in the study list, but related lures were always presented in a different format from their associates in the study list (e.g., a picture of a lock at study, the word key at test). As in Experiments 1 and 2, the studied, related, and unrelated categories consisted of different items.

Procedure. The procedure was identical to that in Experiment 1, except for a slight variation in the instructions. The participants were told that half of the items presented to them would be words and half would be pictures, and that they should focus their attention equally on both formats. In addition, the participants were told that for a test item to be judged "old," both its content and its perceptual format should match the presentation at study.

\section{Results and Discussion}

Table 3 shows the mean proportions of recognized items for Experiment 3. Note that the format (picture or word) specified in the table represents that of the test items. This information is important for the related lures, because they were always presented in a different format from their studied associates.

An ANOVA revealed significant main effects of item type $\left[F(2,78)=678.58, M S_{\mathrm{e}}=0.01, p<.001\right]$ and perceptual format at test $\left[F(1,39)=13.47, M S_{\mathrm{e}}=0.018\right.$, $p<.001]$ and a significant interaction of these two variables $\left[F(2,78)=52.77, M S_{\mathrm{e}}=0.010, p<.001\right]$. Tests of simple effects indicated that item type was significant for the recognition of pictures $\left[F(2,78)=728.56, M S_{\mathrm{e}}=\right.$ $0.008, p<.001]$ and of words $\left[F(2,78)=149.08, M S_{\mathrm{e}}=\right.$ $0.012, p<.001]$. More importantly, $t$ tests revealed that related pictures were falsely recognized at a higher rate than unrelated pictures $[t(39)=7.34, p<.001]$. Similarly, related words were falsely recognized at a higher rate than unrelated words $[t(39)=3.03, p<.005]$. Finally, tests of simple effects showed that the hit rate for studied pictures was significantly greater than the hit rate for studied words $\left[F(1,39)=97.76, M S_{\mathrm{e}}=0.012\right.$, $p<.001]$. In contrast, the rate of false recognition for related pictures did not significantly differ from that for related words $(F<1)$.

These results show that the participants falsely recognized more related than unrelated lures, even though the related lures were in a different format from their studied associates. In other words, the participants falsely recognized a new picture when its semantic associate was studied as a word. Likewise, they falsely recognized a new word when its associate was studied as a picture. These findings provide further evidence for the influence of conceptual relatedness on false recognition and 
Table 3

Experiment 3: Mean Proportions of Test Items Judged "Old" as a Function of Item Type and Perceptual Format at Test (Words vs. Pictures)

\begin{tabular}{lcc}
\hline Item Type & Words & Pictures \\
\hline Studied & .57 & .81 \\
Related & .23 & .24 \\
Unrelated & .17 & .11 \\
\hline
\end{tabular}

Note-For related lures, associates were presented in a different format at study.

highlight the fact that false recognition can occur even when semantically related study and test items differ dramatically in their perceptual surface features and do not share lexical representations.

\section{EXPERIMENT 4}

Experiment 4 examined the subjective experience underlying false recognition. As discussed in the introduction, one view holds that in the context of a memory task, facilitated processing of an item elicits a feeling of familiarity. An alternative view suggests, however, that facilitated processing of an item merely elicits a feeling of processing ease (subjective fluency), which participants then use to make strategic inferences about the status of the item. Both views are consistent with the observations that processing facilitation can influence judgments other than memory, such as liking, duration, or loudness. The difference between the views lies in their assumptions about the qualitative nature of the feeling elicited in the context of a memory task - a specific feeling of familiarity or a general feeling of subjective fluency. Finally, it is also possible that participants do not base their recognition judgments on any feelings. To test these views, we added an attribution manipulation to the cross-format (words vs. pictures) priming procedure used in Experiment 3 . This attribution manipulation has been used successfully in previous research on the role of subjective experiences in judgment (Schwarz et al., 1991): Specifically, we played ambiguous music in the background during the entire experiment. Immediately prior to the second test phase, the participants were informed that this music might elicit a particular feeling (either familiarity or subjective fluency), thus undermining the diagnostic value of that feeling for recognition judgments. If the attribution manipulation targeting the feeling of familiarity or subjective fluency eliminated the false-recognition effects, it would suggest that under normal conditions, the respective feeling contributes to memory judgments. In addition to attributions of familiarity and subjective fluency, we used a nonspecific attribution as a control.

Furthermore, in Experiment 4, we examined a potential issue with stimulus selection in Experiments 1-3. Note that in the experiments presented so far, the studied, related, and unrelated lures consisted of different stimulus items. For example, table was always a related and never an unrelated lure. Although items were in no way systemati- cally assigned to the related and unrelated lure categories, it is possible that related lures were falsely recognized at a higher rate than unrelated lures simply because of the nature of the particular items in each category rather than their relationship to the study items. In order to ensure that this was not the cause of false-recognition effects obtained in the present research, we changed the methodology in Experiment 4. Specifically, the same stimuli served as all three of the item types (studied, related, and unrelated), and this was manipulated between subjects. If we again obtained a false recognition effect, we could be certain it was due to the semantic relationship of test items to study items.

\section{Method}

Participants and Materials. Forty-nine undergraduates from the University of Denver participated for extra course credit. The pictures were 64 common objects and animals from Snodgrass and Vanderwart's (1980) set. Each picture was paired with one semantically associated word, thus forming a total of 64 paired associates in different perceptual formats, as shown in Appendix B. There were two study lists and two test lists, each consisting of 32 items freshly randomized for each participant. Half of the paired associates were presented as words at study and pictures at test, and the other half were presented as pictures at study and words at test. Thus, the study and test lists contained both words and pictures, which were randomly intermixed. In addition, 16 additional filler words unrelated to any of the test items were chosen from Snodgrass and Vanderwart's stimuli for presentation at study. Four experimental scripts were generated and counterbalanced across subjects. Each of the four scripts contained different pairings of study and test items. Specifically, in each of the four scripts, a particular study item (e.g., the word table) was paired in test with either an identical studied item (e.g., table), a semantically related item in a different format (e.g., a picture of a chair), or a semantically unrelated item in a different format (e.g., a picture of a ring), manipulated between subjects. As a result, the studied, related, and unrelated categories of test items consisted of the same stimuli, and each stimulus served as its own control in the other scripts. Each test list contained 16 studied, 8 related, and 8 unrelated items, half pictures and half words. As in Experiments 1-3, test lists never included the actually studied associates of related lures.

Procedure. The procedure was identical to those in Experiments 1-3, except for the added attribution manipulation. For this purpose, new age music was played softly at half speed in the background during the entire experiment. Immediately before the second test list, the participants received additional instructions about the music. There were three between-subjects attribution conditions: (1) familiarity, (2) subjective fluency, and (3) nonspecific feelings. The exact instructions for each condition are in Appendix C. In general, the instructions stated that the background music might elicit a feeling of familiarity or of fluency or have a nonspecific influence. ${ }^{1}$ The participants were told to ignore the respective feeling while making recognition judgments. These instructions were merely a "cover story" designed to lead the participants to consider a particular experience nondiagnostic (the music itself did not actually produce these experiences). After reading these additional instructions, the participants made their judgments for the second test list. Thus, the participants completed the first test list without any additional instructions, but they always read the attribution instructions before the second test list. The items presented in the first and second test lists were counterbalanced across subjects so that the same items were sometimes presented with attribution and other times were presented without attribution. Finally, at the conclusion of the experiment, a manipulation check question 
Table 4

Experiment 4: Mean Proportions of Test Items Judged "Old" as a Function of Item Type and Attribution Condition

\begin{tabular}{lccc}
\hline \multicolumn{1}{c}{ Attribution } & Studied & Related & Unrelated \\
\hline None & .70 & .33 & .22 \\
Familiarity & .76 & .14 & .17 \\
Subjective fluency & .61 & .28 & .22 \\
Nonspecific feelings & .67 & .30 & .15 \\
\hline
\end{tabular}

Note-The None row shows data from the first test list. The Familiarity, Subjective fluency, and Nonspecific feelings rows show data from the later test lists.

assessed whether the participants had followed the additional instructions in making their recognition judgments.

\section{Results and Discussion}

Table 4 presents the mean proportions of items judged "old" as a function of item type (studied, related, or unrelated) and attribution condition (familiarity, subjective fluency, or nonspecific feelings). To simplify the presentation of results, Table 4 shows combined means for the two formats (pictures and words) at test. For the first test list, in which there was no attribution manipulation, an ANOVA revealed a significant main effect of item type $\left[F(2,96)=131.88, M S_{\mathrm{e}}=0.02, p<.001\right]$. More importantly, a further $t$ test revealed that the participants falsely recognized related lures significantly more than unrelated lures $[t(48)=3.44, p=.001]$. Thus, in the noattribution phase, Experiment 4 successfully replicated across perceptual formats the false-recognition effect obtained in Experiment 3.

For the second test list, in which attribution manipulations were added, an ANOVA revealed a significant main effect of item type $\left[F(2,92)=164.21, M S_{\mathrm{e}}=0.02\right.$, $p<.001]$ and a marginally significant interaction of item type and attribution condition $[F(4,92)=2.23$, $\left.M S_{\mathrm{e}}=0.02, p=.07\right]$. More importantly, pairwise comparisons revealed that in the nonspecific feelings condition, related lures were falsely recognized at a higher rate than were unrelated lures $(p<.001)$. This replication of the basic false-recognition effect was expected, as the nonspecific feelings condition was designed to be a control condition. Furthermore, in the subjective fluency condition, related lures were again falsely recognized more than unrelated lures $(p=.056)$. By contrast, in the familiarity condition, the participants no longer falsely recognized related lures more than unrelated lures $(t<1)$. In fact, as shown in Table 4, the falserecognition effect obtained in Experiment 3 and replicated in the no-attribution phase of Experiment 4 was nonsignificantly reversed in the familiarity attribution condition. Thus, when the participants misattributed their feelings of familiarity associated with related lures to an external source (music), false recognition of related lures was eliminated, suggesting that this feeling contributes to false recognition of semantic associates.

Importantly, as can be seen in Table 4, the familiarity attribution did not simply change participants' overall response strategy, but in fact made them more accurate in that they were better able to discriminate studied items from related lures. Specifically, $d^{\prime}$ analyses indicated that discriminability between studied items and related lures was greater in the familiarity condition $(M=1.94$, $S D=1.06)$ than in the fluency condition $(M=0.95$, $S D=0.55)[t(30)=3.30, p<.005]$. Discriminability was also significantly greater in the familiarity condition than in the nonspecific condition $(M=1.08, S D=0.66)$ $[t(31)=2.81, p<.01]$. There was no significant difference between the fluency and nonspecific conditions $(t<1)$. Before conducting these analyses, hit rates of 1.0 and false alarm rates of 0.0 were both adjusted by $.5 \mathrm{~N}$, where $N$ is the number of trials per participant. Similar results were obtained when $A^{\prime}$ was used as a measure of discriminability.

In addition, the differences between the fluency and familiarity attribution conditions were not driven by differences in believability of the manipulation. In response to the manipulation check question "Did you take the information in instructions into account when making your judgments?" 12 out of 16 participants $(75 \%)$ in the familiarity condition answered "yes," and 4 said "no." In the subjective fluency condition, 11 out of the $16(69 \%)$ participants answered "yes," 3 said "no," and 2 left the question blank. The high and approximately equal numbers of "yes" responses indicate that in both conditions, the participants believed the cover story about the music and followed the instructions when making their judgments $\left[\chi^{2}(1, N=30)=0.05, p>.05\right]$.

\section{GENERAL DISCUSSION}

The present study yielded two main results: First, conceptual relatedness enhances false recognition. Specifically, in Experiment 1A, the participants falsely recognized test words that were each semantically related to a single study word. Experiment 1B extended this finding to pictures. In Experiment 2, the participants falsely recognized semantically related lures even when they were presented in a different language from their studied associates (English vs. Spanish). In Experiments 3 and 4, the participants falsely recognized related lures even when they were presented in a different format from their studied associates (words vs. pictures). All of these findings suggest that the influence of conceptual relatedness on memory illusions is a robust phenomenon, as it survives significant changes in surface features, such as stimulus format or even language. The observed falserecognition effects are especially notable given that the present experiments relied on a single-pair recognition paradigm, as opposed to a converging associates paradigm using multiple related items (Roediger \& McDermott, 1995) or a paradigm in which the target word is prepared by an immediately preceding sentence stem (Whittlesea, 1993). This result suggests that even a relatively weak semantic preparation is sufficient to produce a robust false-recognition effect. Second, the results of 
Experiment 4 support the notion that the subjective experience underlying false recognition is a feeling of familiarity. Specifically, when participants attributed familiarity to an external source, the semantic false recognition was eliminated. Significantly, the attribution of subjective fluency and nonspecified feelings did not significantly reduce semantic false recognition, even though these manipulations were perceived as believable. This finding fits well with the idea of the experiential basis of memory judgments (e.g., Jacoby et al., 1989; Whittlesea \& Williams, 1998).

\section{False Recognition Rate}

Before we further discuss the implications of our results, it will be useful to address a potentially puzzling finding. In the present research, the increases in false recognition from unrelated to related lures were consistent and robust, in the range of $6 \%-15 \%$. The overall rate of false recognition for related lures, however, ranged between $21 \%$ and $37 \%$, which is lower than the falserecognition rates in DRM experiments, in which the false alarm rates can sometimes exceed 70\% (Roediger $\&$ McDermott, 1995). This anomaly is probably due to several differences between the paradigms. First, studying only one associate of the related lure generates a weaker trace than studying multiple (e.g., 18) converging associates in the DRM paradigm. Second, our singlepair paradigm does not contain any list themes, which could in certain circumstances be used to "recognize" a critical lure.

\section{Accounts of False Recognition}

There are several accounts of false recognition effects like those obtained in the present study. One account posits that processing study items leads to implicit associative responses, or conscious thinking of other semantically related items (Underwood, 1965). However, results of several recent studies using the DRM paradigm indicate that false recognition results from automatic activation of related lures during processing of study items (Gallo et al., 1997; Roediger et al., 2002; Seamon et al., 2002; Seamon et al., 1998). The present findings fit well with the idea that false recognition for related lures is driven by automatic processes. After all, it is unlikely that during the presentation of study items participants generated a related word (Experiment 1A), a related picture (Experiment $1 \mathrm{~B})$, a related word in a different language (Experiment 2), or both a picture related to each presented word and a word related to each presented picture (Experiments 3 and 4).

More light on the present results can be shed by the fuzzy trace theory (FTT) (Brainerd et al., 2003). This theory posits that memory judgments can be based on verbatim or gist traces encoded during the study episode. Verbatim traces represent the surface, physical details of the stimuli, whereas gist traces represent the meaning of the stimuli. In the DRM paradigm, gist traces may represent the general thematic content of the study list-for ex- ample, anger for the list containing the words mad, fear, hate, and so forth (Payne, Elie, Blackwell, \& Neuschatz, 1996). Thus, the FTT predicts that false-recognition effects are due to a match between stored gist traces from the study episode and the related lures embedded in the test list. In the single-pair paradigm, gist traces from the study list are likely to be significantly weaker than in the DRM paradigm. In accord with this explanation, the effects were significantly reduced in the present study as compared with those from previous research using the DRM paradigm. Furthermore, the FTT nicely accounts for why robust false-recognition effects were still obtained in our experiments, despite significant changes in surface-level features between study and test. Under these conditions, related lures are less likely to provoke the retrieval of verbatim traces of their associates in the study list. Verbatim retrieval serves to suppress false recognition via a process of recollection rejection, the vivid recollection of surface form information from study and the rejection of an associated test item based on that recollection (e.g., "I must not have seen table because I specifically remember seeing chair."). If verbatim retrieval is reduced when surface form is changed, then recollection rejection is less likely, and the tendency toward semantic false recognition is increased. Thus, according to the FTT, even though changing surface form reduces overall activation of related lures, the reduction of verbatim retrieval cancels out this effect, and semantic false recognition is preserved (see Brainerd et al., 2003, for a recent review and Gerkens \& Smith, 2004, for a recent test).

False recognition in the DRM paradigm has also been interpreted with a global matching hypothesis derived from the MINERVA2 memory model (Arndt \& Hirshman, 1998; Hintzman, 1988). This model sees false recognition as due to the global similarity of the related lure to the whole set of studied items (i.e., all converging associates). Our findings using the single-pair paradigm fit this model; however, instead of sharing features with the whole set of studied items in the DRM paradigm, our lures share some features with only one related study item.

It is worth pointing out, however, that the similarity of study and test items is not sufficient to explain the psychological mechanisms underlying false recognition. Whittlesea (2002) argues in his discrepancy attribution theory that false recognition arises via a two-step process. First, facilitated processing of related lures is interpreted as discrepant from expected processing. Second, in the memory context, this surprising discrepancy generates the subjective experience of familiarity, which drives judgments of previous occurrence (Whittlesea \& Williams, 1998). This account fits well with several aspects of the present findings: First, the discrepancy attribution theory explains why robust effects of conceptual relatedness on false recognition can emerge in a paradigm in which each related lure is prepared by only one semantically related study item, as opposed to the 18 study items typically used in the DRM paradigm. Al- 
though the processing facilitation with just one study item is relatively weak, it is unobtrusive and does not generate an expectation about faster processing of a related lure. In addition, facilitation by conceptual rather than perceptual priming may be particularly effective in generating a feeling of familiarity, given that fast conceptual processing occurs against the expectations set by slow perceptual processing (Whittlesea, 2002). The second aspect of our findings that fits well with the discrepancy attribution theory is that related lures produce a subjective experience of familiarity, which then drives the recognition judgments. Accordingly, in Experiment 4, false recognition disappeared when a feeling of familiarity was made nondiagnostic, but remained high when participants were encouraged to find other experiences nondiagnostic, such as subjective fluency or nonspecific feelings. Of course, the fact that misattribution of $s u b$ jective fluency (feeling of ease) was ineffective does not contradict the idea that changes in objective fluency (processing speed) underlie a subjective feeling of familiarity. It simply suggests that in the context of making memory judgments, the fluency-based subjective experience takes the shape of a feeling of familiarity.

Our finding that the feeling of familiarity underlies semantic false recognition is particularly important because to our knowledge, this issue has never been tested directly with manipulations targeting subjective experiences, despite many proposals referring to this idea (Jacoby et al., 1989; Whittlesea \& Williams, 1998). Thus, the present study extends research that has explored familiarity using physiological measures (Curran, 2000), manipulations of stimulus properties (Norman, 2002), computational modeling (O'Reilly \& Norman, 2002), and neuropsychological methods (Yonelinas, 2002). Importantly, however, the subjective experience associated with processing facilitation might change depending on the context of the judgment task. For example, in the context of a liking judgment, processing facilitation may elicit affective feelings rather than feelings of familiarity (Winkielman, Schwarz, Fazendeiro, \& Reber, 2003).

In conclusion, the present experiments clearly show that conceptual relatedness can produce false recognition even in the absence of shared perceptual surface features between study and test items. Furthermore, our research shows the subjective experience underlying this effect to be a feeling of familiarity for the related lure. As such, our experiments facilitate a better understanding of the fascinating phenomena of memory illusions.

\section{REFERENCES}

Arndt, J., \& Hirshman, E. (1998). True and false recognition in MINERVA2: Explanations from a global matching perspective. Journal of Memory \& Language, 39, 371-391.

Brainerd, C. J., Reyna, V. F., Wright, R., \& Mojardin, A. H. (2003). Recollection rejection: False-memory editing in children and adults. Psychological Review, 110, 762-784.

CARAMAZZA, A., \& Brones, I. (1980). Semantic classification by bilinguals. Canadian Journal of Psychology, 34, 77-81.
Chumbley, J. I., \& Balota, D. A. (1984). A word's meaning affects the decision in lexical decision. Memory \& Cognition, 12, 590-606.

Curran, T. (2000). Brain potentials of recollection and familiarity. Memory \& Cognition, 28, 923-938.

DEESE, J. (1959). On the prediction of occurrence of particular verb intrusions in immediate recall. Journal of Experimental Psychology, 58, 17-22.

Gállo, D. A., McDermott, K. B., Percer, J. M., \& Roediger, H. L., III (2001). Modality effects in false recall and false recognition. Journal of Experimental Psychology: Learning, Memory, \& Cognition, 27, 339-353.

Gallo, D. A., Roberts, M. J., \& Seamon, J. G. (1997). Remembering words not presented in lists: Can we avoid creating false memories? Psychonomic Bulletin \& Review, 4, 271-276.

Gerkens, D. R., \& SMith, S. M. (2004). Effects of perceptual modality on verbatim and gist memory. Psychonomic Bulletin \& Review, 11, 143-149.

Grossman, L., \& Eagle, M. (1970). Synonymity, antonymity, and association in false recognition responses. Journal of Experimental Psychology, 83, 244-248.

Hintzman, D. L. (1988). Judgments of frequency and recognition memory in a multiple-trace memory model. Psychological Review, 95, 528-551.

ISRAEL, L., \& SCHACTER, D. L. (1997). Pictorial encoding reduces false recognition of semantic associates. Psychonomic Bulletin \& Review, 4, 577-581.

JaC̄oby, L. L., Allan, L. G., Collins, J. C., \& Larwill, L. K. (1988). Memory influences subjective experience: Noise judgments. Journal of Experimental Psychology: Learning, Memory, \& Cognition, 14, 240-247.

JACOBY, L. L., \& DALlas, M. (1981). On the relationship between autobiographical memory and perceptual learning. Journal of Experimental Psychology: General, 110, 306-340.

JACOBY, L. L., Kelley, C. M., \& DYWAN, J. (1989). Memory attributions. In H. L. Roediger III \& F. I. M. Craik (Eds.), Varieties of memory and consciousness: Essays in honour of Endel Tulving (pp. 391422). Hillsdale, NJ: Erlbaum.

JACOBY, L. L., \& WhiteHouse, K. (1989). An illusion of memory: False recognition influenced by unconscious perception. Journal of Experimental Psychology: General, 118, 126-135.

Johnston, W. A., Hawley, K. J., \& ELliot, J. M. G. (1991). Contribution of perceptual fluency to recognition judgments. Journal of Experimental Psychology: Learning, Memory, \& Cognition, 17, 210223.

Lindsay, D. S., \& Kelley, C. M. (1996). Creating illusions of familiarity in a cued recall remember/know paradigm. Journal of Memory \& Language, 35, 197-211.

LUO, C. R. (1993). Enhanced feeling of recognition: Effects of identifying and manipulating test items on recognition memory. Journal of Experimental Psychology: Learning, Memory, \& Cognition, 19, 405413.

Mandler, G., NaKamura, Y., \& Van Zandt, B. J. S. (1987). Nonspecific effects of exposure on stimuli that cannot be recognized. Journal of Experimental Psychology: Learning, Memory, \& Cognition, 15, 646-648.

Masson, M. E. J., \& Caldwell, J. I. (1998). Conceptually driven encoding episodes create perceptual misattributions. Acta Psychologica, 98, 183-210.

NORMAN, K. A. (2002). Differential effects of list strength on recollection and familiarity. Journal of Experimental Psychology: Learning, Memory, \& Cognition, 28, 1083-1094.

O'REILLY, R. C., \& NORMAN, K. A. (2002). Hippocampal and neocortical contributions to memory: Advances in the complementary learning systems framework. Trends in Cognitive Sciences, 12, 505-510.

Paivio, A., Rogers, T. B., \& Smythe, P. C. (1968). Why are pictures easier to recall than words? Psychonomic Science, 11, 137-138.

Payne, D. G., Elie, C. J., Blackwell, J. M., \& Neuschatz, J. S. (1996). Memory illusions: Recalling, recognizing, and recollecting events that never occurred. Journal of Memory \& Language, 35, 261285 . 
RAJARAM, S. (1993). Remembering and knowing: Two means of access to the personal past. Memory \& Cognition, 21, 89-102.

Reber, R., Winkielman, P., \& SchWarz, N. (1998). Effects of perceptual fluency on affective judgments. Psychological Science, 9, 4548.

ReIsenZein, R. (1983). The Schachter theory of emotion: Two decades later. Psychological Bulletin, 94, 239-264.

Roediger, H. L., III, Balota, D. A., \& RoBInson, K. J. (2002). Automatic mechanisms in the arousal of false memories. Unpublished manuscript, Washington University, St. Louis, MO.

Roediger, H. L., III, \& McDermott, K. B. (1995). Creating false memories: Remembering words not presented in lists. Journal of Experimental Psychology: Learning, Memory, \& Cognition, 21, 803814.

SCHAChter, S., \& Singer, J. E. (1962). Cognitive, social, and physiological determinants of emotional state. Psychological Review, $\underline{69}_{2}$ 379-399.

Schwarz, N., Bless, H., Strack, F., Klumpr, G., RittenauerSCHATKA, H., \& SimONS, A. (1991). Ease of retrieval as information: Another look at the availability heuristic. Journal of Personality \& Social Psychology, 61, 195-202.

SCHWARZ, N., \& CLORE, G. L. (1996). Feelings and phenomenal experiences. In E. T. Higgins \& A. Kruglanski (Eds.), Social psychology: Handbook of basic principles (pp. 433-465). New York: Guilford.

Seamon, J. G., Lee, I. A., Toner, S. K., Wheeler, R. H., Goodkind, M. S., \& BIRCH, A. D. (2002). Thinking of critical words during study is unnecessary for false memory in the Deese, Roediger, and McDermott procedure. Psychological Science, 13, 526-531.

Seamon, J. G., Luo, C. R., \& Gallo, D. A. (1998). Creating false memories of words with or without recognition of list items: Evidence for nonconscious processes. Psychological Science, 9, 20-26.

SMITH, M. C. (1991). On the recruitment of semantic information for word fragment completion: Evidence from bilingual priming. Journal of Experimental Psychology: Learning, Memory, \& Cognition, 17, 234-244.

SNODGRASS, J. G., \& VANDERwART, M. (1980). A standardized set of 260 pictures: Norms for naming agreement, familiarity, and visual complexity. Journal of Experimental Psychology: Human Learning \& Memory, 6, 174-215.

Tulving, E. (1985). Memory and consciousness. Canadian Psychologist, 26, 1-12.
UNDERWOOD, B. J. (1965). False recognition produced by implicit verbal responses. Journal of Experimental Psychology, 70, 122-129.

Verfaellie, M., \& Treadwell, J. R. (1993). Status of recognition memory in amnesia. Neuropsychology, 7, 5-13.

Watkins, M. J., \& PeYNIRCIOǦLU, Z. F. (1983). On the nature of word recall: Evidence for linguistic specificity. Journal of Verbal Learning \& Verbal Behavior, 22, 385-394.

Weldon, M. S., Roediger, H. L., III, Beitel, D. A., \& Johnson, T. R. (1995). Perceptual and conceptual processes in implicit and explicit tests with picture fragment and word fragment cues. Journal of Memory \& Language, $34,268-285$.

WhitTleseA, B. W. A. (1993). Illusions of familiarity. Journal of Experimental Psychology: Learning, Memory, \& Cognition, 19, 12351253.

Whittlesea, B. W. A. (2002). False memory and the discrepancyattribution hypothesis: The prototype-familiarity illusion. Journal of Experimental Psychology: General, 131, 96-115.

WhitTlesea, B. W. A., JACOBY, L. L., \& Girard, K. (1990). Illusions of immediate memory: Evidence of an attributional basis for feelings of familiarity and perceptual quality. Journal of Memory \& Language, 29, 716-732.

Whittlesea, B. W. A., \& Williams, L. D. (1998). Why do strangers feel familiar, but friends don't? A discrepancy-attribution account of feelings of familiarity. Acta Psychologica, 98, 141-165.

Winkielman, P., Schwarz, N., Fazendeiro, T., \& Reber, R. (2003). The hedonic marking of processing fluency: Implications for evaluative judgment. In J. Musch \& K. C. Klauer (Eds.), The psychology of evaluation: Affective processes in cognition and emotion (pp. 189217). Mahwah, NJ: Erlbaum.

Yonelinas, A. P. (2002). The nature of recollection and familiarity: A review of 30 years of research. Journal of Memory \& Language, $\underline{\mathbf{4 6}}$, $\underline{441-517 .}$

\section{NOTE}

1. The majority of the participants ( 10 out of 16$)$ in this condition reported that the music had an influence on their feelings. Specifically, in response to the manipulation check question "How did the music make you feel?" 7 described affective feelings, 2 described cognitive feelings, and 1 described both cognitive and affective feelings. The remaining 6 participants indicated that the music produced no feelings in them.

\section{Paired Associates Used in Experiments 1, 2, and 3}

table-chair

lock-key

shoe-sock

car-truck

wrench-pliers

watch-clock

stove-refrigerator

apple-orange

toaster-bread

football-helmet

brush-comb

bottle-wineglass

screwdriver-screw

glasses-eye

moon-star

anchor-boat cannon-gun

thimble-thread

baseball bat-ball

vase-flower

finger-hand

shirt-pants

lamp-light bulb

knife-fork

door-window

arm-leg

hammer-nail

ironing board-iron

crib-baby

leaf-tree

ashtray-cigarette

dog-cat 
APPENDIX B

Paired Associates Used in Experiment 4

\begin{tabular}{|c|c|c|c|}
\hline Words & Pictures & Pictures & Words \\
\hline $\log$ & axe & fish & hook \\
\hline charcoal & barbecue & baby & crib \\
\hline pillow & bed & arm & leg \\
\hline honey & bee & cat & dog \\
\hline buckle & belt & star & moon \\
\hline skirt & blouse & nail & hammer \\
\hline stump & branch & sock & shoe \\
\hline snow & shovel & chair & table \\
\hline water & glass & key & lock \\
\hline desert & camel & orange & apple \\
\hline carrot & rabbit & truck & car \\
\hline smoke & chimney & stove & refrigerator \\
\hline priest & church & thread & needle \\
\hline milk & cow & baseball bat & ball \\
\hline coffee & mug & cherry & pie \\
\hline stamp & envelope & lamp & bulb \\
\hline feather & bird & fork & knife \\
\hline clothes & hanger & shirt & tie \\
\hline party & gift & door & window \\
\hline acorn & squirrel & bread & butter \\
\hline palette & paintbrush & football & helmet \\
\hline rain & umbrella & comb & hair \\
\hline egg & chicken & bottle & wineglass \\
\hline web & spider & screw & screwdriver \\
\hline stem & flower & eye glasses & eye \\
\hline whistle & train & anchor & boat \\
\hline foot & hand & gun & bullet \\
\hline paper & pencil & leaf & tree \\
\hline coat & hat & wrench & bolt \\
\hline student & desk & ashtray & cigarette \\
\hline fire & hydrant & ironing board & iron \\
\hline ear & nose & bear & lion \\
\hline
\end{tabular}

\section{APPENDIX C \\ Instructions for Attribution Manipulations \\ Used in Experiment 4}

Familiarity. In this part of the experiment, we are also interested in one more thing. You probably noticed the music playing in the background. We are concerned about the possible effects of this music on your memory judgments. Specifically, according to our earlier research, this music may have an effect of inducing a feeling of familiarity. That is, the music can occasionally make you feel like you've seen or read something before, giving you a sense of knowing that item. In order for us to assess this potential effect of music, we would like you to make the next set of memory judgments ignoring your feeling of familiarity. Simply, don't make your judgments using the sense that an item is familiar.

Subjective fluency. In this part of the experiment, we are also interested in one more thing. You probably noticed the music playing in the background. We are concerned about the possible effects of this music on your memory judgments. Specifically, according to our earlier research, this music may have an effect of inducing a feeling of fluency. That is, the music can occasionally make you feel like your thoughts come to mind with greater ease or speed, giving you a sense of items "popping out in your mind" more easily. In order for us to assess this potential effect of music, we would like you to make the next set of memory judgments ignoring your feeling of fluency. Simply, don't make your judgments using the sense that an item comes to mind easily or quickly.

Nonspecific feelings. In this part of the experiment, we are also interested in one more thing. You probably noticed the music playing in the background. We are concerned about the possible effects of this music on your memory judgments. In order for us to assess these potential effects, we would like you to make the next set of memory judgments ignoring the effects of the background music. 